\title{
(2) OPEN ACCESS \\ Return to play with hypertrophic cardiomyopathy: are we moving too fast? A critical review
}

\author{
Jonathan A Drezner ํㅏ, ${ }^{1}$ Aneil Malhotra 지, ${ }^{2}$ Jordan M Prutkin, ${ }^{3}$ Michael Papadakis, \\ Kimberly G Harmon (1) , ${ }^{1}$ Irfan M Asif, ${ }_{1}^{5}$ David S Owens, ${ }^{3}$ Joseph C Marek, ${ }^{6}$ \\ Sanjay Sharma ${ }^{4}$
}

${ }^{1}$ Center for Sports Cardiology, University of Washington, Seattle, Washington, USA ${ }^{2}$ Division of Cardiovascular Sciences, University of Manchester, Manchester, UK ${ }^{3}$ Department of Internal Medicine, Division of Cardiology, University of Washington, Seattle, Washington, USA ${ }^{4}$ Cardiology, Clinical Academic Group, St George's, University of London, London, UK

${ }^{5}$ Center for Health Promotion, University of Alabama at Birmingham, Birmingham, Alabama, USA

${ }^{6}$ Cardiology, Advocate Heart Institute, Downers Grove, Illinois, USA

\section{Correspondence to} Dr Jonathan A Drezner, Center for Sports Cardiology, University of Washington, Seattle,

Washington, USA jdrezner@uw.edu

Accepted 3 December 2020 Published Online First 20 January 2021

\section{Linked}

http://dx.doi.org/10.1136/ bjsports-2020-101987

Check for updates

(C) Author(s) (or their employer(s)) 2021. Re-use permitted under CC BY-NC. No commercial re-use. See rights and permissions. Published by BMJ.

To cite: Drezner JA, Malhotra A, Prutkin JM et al. Br J Sports Med 2021:55:1041-1048.

\section{ABSTRACT}

The diagnosis of a potentially lethal cardiovascular disease in a young athlete presents a complex dilemma regarding athlete safety, patient autonomy, team or institutional risk tolerance and medical decision-making. Consensus cardiology recommendations previously supported the 'blanket' disqualification of athletes with hypertrophic cardiomyopathy (HCM) from competitive sport. More recently, epidemiological studies examining the relative contribution of $\mathrm{HCM}$ as a cause of sudden cardiac death (SCD) in young athletes and reports from small cohorts of older athletes with HCM that continue to exercise have fueled debate whether it is safe to play with HCM. Shared decision-making is endorsed within the sports cardiology community in which athletes can make an informed decision about treatment options and potentially elect to continue competitive sports participation. This review critically examines the available evidence relevant to sports eligibility decisions in young athletes diagnosed with HCM. Histopathologically, HCM presents an unstable myocardial substrate that is vulnerable to ventricular tachyarrhythmias during exercise. Studies support that young age and intense competitive sports are risk factors for SCD in patients with HCM. We provide an estimate of annual mortality based on our understanding of disease prevalence and the incidence of HCM-related SCD in different athlete populations. Adolescent and young adult male athletes and athletes participating in a higher risk sport such as basketball, soccer and American football exhibit a greater risk. This review explores the potential harms and benefits of sports disqualification in athletes with HCM and details the challenges and limitations of shared decision-making when all parties may not agree.

'Medicine is a science of uncertainty and an art of probability'.-William Osler (1849-1919)

\section{INTRODUCTION}

Sudden cardiac arrest (SCA) is the leading cause of sudden death in young competitive athletes during sports and exercise. ${ }^{1-3}$ The aetiology of SCA in young athletes ( $<30$ years of age) includes a diverse group of genetic and congenital cardiac diseases such as cardiomyopathies, ion channel disorders and anomalous coronary arteries. Early detection of conditions at elevated risk of SCA through cardiovascular screening allows the potential for risk reduction by disease-specific management and individualised activity restrictions. ${ }^{4}$ In 2005 , both the American Heart Association (AHA) and European Society of Cardiology (ESC) advised the routine disqualification of athletes from competitive sport following the diagnosis of a potentially sinister cardiac disorder capable of causing sudden cardiac death (SCD). ${ }^{5}{ }^{6}$ However, new guidelines by the AHA/American College of Cardiology (2015) and the ESC/European Association of Preventive Cardiology (2019) no longer support a simple binary 'yes/no' approach to sports eligibility decisions. ${ }^{78}$

Pelliccia et al recently reported results in adult patients with hypertrophic cardiomyopathy (HCM) and the risk of major adverse cardiovascular events with and without continued sports participation. ${ }^{9}$ In 88 adult athletes (median age 31 years) with a predominantly low-risk HCM phenotype followed for a 7-year period, the study found no difference in the risk of SCA in patients choosing to continue competitive sports versus those who selected out of intensive exercise. ${ }^{9}$ While the study lacks power to draw definitive conclusions, the results provide important data to inform activity recommendations in middle-aged adult athletes with HCM. However, the authors appropriately caution that these results should not be applied to adolescent and younger adult athletes or those with a more severe HCM phenotype where the risk of SCD with intensive exercise may be higher.

How should these results impact a rapidly evolving paradigm for sports eligibility decisions in athletes identified with conditions at risk for SCA/ SCD? This review addresses the principles and limitations of shared decision-making in the context of a potentially lethal cardiovascular disorder, with specific focus on the risks and current controversy of allowing competitive athletes with HCM to return to play. A critical analysis of HCM-related SCD is presented to guide evidence-informed sports eligibility decisions. While not the primary intent of this review, the information presented may be applicable to young persons diagnosed with HCM who wish to engage in recreational sports and exercise.

\section{SHARED DECISION-MAKING IN SPORTS CARDIOLOGY}

Shared decision-making is a collaborative process between the patient, other stakeholders (eg, parents) and the physician that combines the principles of informed consent and patient autonomy. ${ }^{1011}$ A shared decision-making approach considers the values and preferences of the patient and is especially important when more than one management option is reasonable. Within sports cardiology eligibility decisions, all stakeholders in the outcome are ideally involved in the decision process with 
consent from the patient (or parents of children), including family members, athletic trainers, physiotherapists, team physicians, cardiologists, coaches and team, school or club officials. A thoughtful discussion of the potential harms and benefits of different treatment options, including continued competitive sports participation, should be explored using the best available evidence. Ideally, the final decision should be acceptable to all parties.

A paradigm shift has evolved regarding a return to sport for competitive athletes diagnosed with cardiovascular disease. ${ }^{10} 12$ Disorders that once led to universal sports disqualification are now considered for return to play on a case-by-case basis. Shared decision-making in sports cardiology was first highlighted in young individuals with long QT syndrome (LQTS). ${ }^{13}$ Two observational studies both reported that young athletes with genotype-positive LQTS who underwent appropriate counselling, optimal medical management and remained treatment compliant could return to sport with a low rate of SCA and no increase in mortality. ${ }^{13} 14$

However, risk mitigation for other cardiovascular diseases that afflict young athletes may not be possible. For instance, compelling data indicate that intense exercise increases the risk of ventricular arrhythmias and disease progression in patients with arrhythmogenic cardiomyopathy. ${ }^{15-18}$ Indeed, recommendations against competitive sports for patients diagnosed with arrhythmogenic cardiomyopathy remain universally supported among sports cardiology experts. Thus, patient autonomy regarding sports participation is not absolute, and shared decision-making should not be oversimplified as a process where the athlete simply makes the decision.

\section{HCM-RELATED SCD IN THE YOUNG}

How should we approach shared decision-making for athletes diagnosed with HCM? Specifically, is there evidence that vigorous exercise or competitive sport increases SCD risk in young athletes with HCM and would exercise restrictions lower their risk? Conversely, is there a subgroup of athletes with HCM who may be able to safely participate in intensive exercise?

Although SCD in sport is relatively uncommon, HCM is frequently diagnosed at autopsy in young athletes, especially in countries without systematic inclusion of a 12-lead ECG in the preparticipation screening programme. Such circumstantial evidence supports that HCM is associated with SCD in young competitive athletes. However, the actual proportion of cases attributable to HCM is variable and may be dependent on the quality of the postmortem examination to differentiate HCM from left ventricular hypertrophy (LVH) commonly found in athletes. In a series of 1306 athletes with SCD in the USA, 842 had an autopsy-confirmed cardiovascular diagnosis. HCM was the leading identified structural disorder representing $36 \%$ of confirmed diagnoses and $23 \%$ of all cardiovascular cases. ${ }^{3}$ An analysis of SCD in college athletes from the USA as well as a prospective study of elite adolescent soccer players from the UK both found that HCM represented about one-third of SCD cases (33\%-37\%). ${ }^{19}{ }^{20}$ While other studies have reported a lower proportion of SCD cases due to HCM (6\%-16\%), HCM remains an important cause of SCD in young athletes. ${ }^{122122}$

Early studies also demonstrated that SCD is more common in younger patients with HCM. A 1982 report examined autopsy and patient records in 78 patients with HCM from the National Heart, Lung, and Blood Institute and found that $71 \%$ of SCD cases occurred before age $30 \%$ and $63 \%$ of these occurred during exertion. ${ }^{23}$ A 2000 report of 86 patients with
HCM-related deaths also found that SCD was more common in younger patients (age 5-25 years) compared with HCM-related stroke and heart failure as the cause of death in older patients. ${ }^{24}$ A Portuguese registry of 1042 patients with HCM (mean age $53 \pm 16$ years) also found that heart failure was the most common cause of death in older patients. ${ }^{25}$

\section{ANNUAL SCD MORTALITY RATE IN PATIENTS WITH HCM}

The risk of SCD in patients with HCM is impacted by several factors including age, symptoms, family history, disease morphology and electrodiagnostics. Early studies reported an annual mortality rate of approximately $4 \%$ in children with HCM. $^{26}{ }^{27}$ In a 1976 study of 35 children with HCM (age $<15$ years) followed for 7.4 years, one-third of patients died suddenly (4\% mortality per year). ${ }^{26}$ Similarly, a 1984 study examined 37 children (ages 1-14 years at diagnosis) followed for 9 years and reported an annual mortality rate of $4.3 \% .^{27}$ More recently, a 2011 study from the National Institute of Health followed 131 younger patients ( $\leq 20$ years of age) for a median of 6.4 years. ${ }^{28}$ The annual rate of sudden death or life-threatening arrhythmic events was $2 \%$, with a mean age of 20.1 years at the time of the arrhythmic event and a higher risk if septal thickness was $\geq 20 \mathrm{~mm}^{28}$

Conventional risk markers for patients with HCM include a prior cardiac arrest, family history of HCM-related sudden death, unexplained recent syncope, multiple episodes of nonsustained ventricular tachycardia (VT), massive LVH (wall thickness $\geq 30 \mathrm{~mm}$ ), left ventricular apical aneurysm or an ejection fraction $<50 \% 0 .{ }^{29}$ Other potential risk mediators include extensive late gadolinium enhancement on cardiac MRI, a hypotensive response to exercise, or marked left ventricular outflow tract obstruction at rest. Patients with one or more major risk markers have a primary indication for an implantable cardioverter defibrillator (ICD) and a predicted event rate for VT or ventricular fibrillation (VF) of $4 \%$ per year. ${ }^{29}$

Risk stratification and selective use of ICDs have greatly improved HCM-related mortality. ${ }^{30-33}$ In 474 younger patients with HCM between 7 and 29 years (mean age 20) with an average follow-up of 7.1 years, 5-year and 10-year survival with application of existing cardiovascular treatment strategies was $97 \%$ and $94 \%$, respectively. ${ }^{30}$ Sixty-three patients experienced sudden death, resuscitated cardiac arrest or appropriate ICD intervention-an annual risk of $1.8 \%$ per year including non-fatal HCM events. ${ }^{30}$ Predictors of HCM mortality and nonfatal aborted events after multivariate analysis included younger age at diagnosis, increased left atrial dimension and greater left ventricular thickness. ${ }^{30}$

Survival has also improved in older adults with HCM through an enhanced American College of Cardiology/AHA risk stratification model combined with contemporary management strategies. In a cohort of 2094 patients with HCM (mean age 51), 527 received primary prevention ICDs. During a mean follow-up of 4.7 years, $82(15.6 \%)$ patients experienced device terminated VT/VF and no patient with an ICD died from SCD. ${ }^{33}$ In the 1567 patients without an ICD, $12(0.8 \%)$ had SCA/SCD, of which 7 patients had high-risk indicators but declined an ICD. ${ }^{33}$ Overall, the annual mortality rate was only $0.1 \%$, supporting that a modern risk stratification and prevention model may avert most SCD in a general population of predominantly older patients with HCM. ${ }^{33}$

Limited data are available regarding the use of ICDs in competitive athletes with HCM. The ICD sports safety registry studied 328 patients (mean age 33 years) for ICD events over a 
median follow-up of 31 months and documented no deaths or resuscitated cardiac arrests. ${ }^{34}$ However, within this cohort, only 60 patients were considered competitive athletes and only 13 had HCM. ${ }^{34}$ This study provides initial evidence that continued sports participation for patients with HCM and an ICD may be safe, although the small sample size does not allow for definitive conclusions.

\section{RACE, SPORT AND HCM-RELATED SCD}

There is a potential association of race and HCM-related SCD in young athletes. ${ }^{35}$ In an autopsy-confirmed series of 842 cases of SCD in athletes (aged $19 \pm 6$ years) in the USA, the cardiovascular death rate was fivefold higher among African Americans and other minorities than among whites $(1: 12778$ vs $1: 60746$ athlete-years; $\mathrm{p}<0.001$ ), and HCM accounted for $42 \%$ of cases in African Americans and other minorities versus 31\% of cases in white athletes $(\mathrm{p}<0.001) .^{3}$ Similarly, in a prospective study of SCA/SCD in US competitive athletes including 19 HCM-related cases, HCM represented $30.3 \%$ of confirmed diagnoses in male African American athletes compared with only $10.0 \%$ of male white athletes $(p=0.0186){ }^{2}$ In contrast, a study of 425 older patients with HCM (163 black and 262 white; mean age 52.5 years) from the UK found no difference in the composite primary outcome of cardiovascular death, cardiac arrest or appropriate device therapy over a mean follow-up of 4.3 years (KaplanMeier survival analysis, $\mathrm{p}$ logrank $=0.095) .{ }^{36}$ These divergent findings regarding the relationship of race and SCD may reflect a difference in risk between young athletes engaging in strenuous exercise compared with a more benign clinical course in older patients with HCM. In addition, the higher prevalence of HCM as a cause of SCD among young black athletes may be in part ascribed to a greater increase in physiological LVH in Afro-Caribbean athletes that can be misinterpreted as HCM at postmortem examination. ${ }^{3738}$

HCM also accounts for a higher proportion of cases in male basketball (23.3\%) and American football (25\%) athletes than in other sports. ${ }^{2}$ Studies examining US college athletes also have documented higher rates of cardiomyopathy as a cause of SCD in male basketball and American football athletes. ${ }^{119}$ Similarly, in a prospective study of adolescent soccer players (95\% male), HCM accounted for 3 of 8 (37\%) SCD cases observed over a mean follow-up period of 10.6 years. ${ }^{20}$ Thus, HCM may represent a disproportionate number of SCA/SCD events in higher risk athlete groups-younger black athletes, male basketball, male soccer and American football-underscoring the need for additional caution when considering a return to competitive sports within these risk groups.

\section{CAN WE QUANTIFY THE RISK OF SCD IN ATHLETES WITH $\mathrm{HCM}$ ?}

SCD from HCM is inherently unpredictable. We have little understanding of the inciting event that suddenly leads to a lethal ventricular tachyarrhythmia in athletes who may have harboured their disease for years. Furthermore, the stresses of the athletic arena are not fully reflected in laboratory testing, highlighting the need for large longitudinal studies. Risk calculators have been developed but are not applicable to young athletes. For example, the ESC HCM Risk-SCD Score estimates the 5-year risk of SCD in patients with HCM but specifically states it should not be used in elite/competitive athletes or paediatric patients $<16$ years.

While the precise risk of SCD in a young athlete with HCM is challenging to predict, an estimate of risk can be drawn from our current understanding of disease prevalence and the incidence of
SCD in competitive athletes (table 1). Based on the annual incidence of SCD in prior studies, the proportion of HCM-related SCD and a disease prevalence from 1:2000 to 1:500 in athletes, we estimate the annual risk of SCD in young athletes with HCM is between $0.1 \%$ and $6.6 \%$ per year depending on the athlete population. ${ }^{1239}$ While the risk may exceed the upper limit of what was calculated, the estimated range is consistent with annual mortality rates previously reported in younger patients with HCM. ${ }^{28} 30$ However, the spectrum of disease phenotypes in athletes is likely less severe than that in the general population, as athletes competing at a high level may not exhibit high-risk phenotypes that could potentially impede athletic performance (ie, greater maximum wall thickness or high left ventricular outflow tract gradients). Phenotypic features of the athletic HCM heart were reported in 106 young athletes (14-35 years) with HCM and compared with 101 sedentary patients with $\mathrm{HCM}^{40}$ Athletes with HCM had milder LVH $(15.8 \pm 3.4 \mathrm{~mm}$ vs $19.7 \pm 6.5 \mathrm{~mm}, \mathrm{p}<0.001)$ that was frequently confined to the apex $(36 \%)$, larger left ventricular cavity dimensions $(47.8 \pm 6.0 \mathrm{~mm}$ vs $44.3 \pm 7.7 \mathrm{~mm}, \mathrm{p}<0.001)$ and superior indices of diastolic function (average $\mathrm{E} / \mathrm{E}^{\prime} 7.9 \pm 2.4$ vs $10.7 \pm 3.9$, $\mathrm{p}<0.001$ ) compared with sedentary patients with HCM. ${ }^{40}$

Our estimates are influenced by the reported incidence of SCD in the athlete population, and higher mortality rates were calculated in black athletes, male athletes and athletes in higher risk sports such as basketball and soccer. Importantly, estimates do not account for resuscitated cardiac arrest in which survival has been reported in up to $48 \%$ of athlete cases. ${ }^{41}$ Thus, the annual risk of any life-threatening ventricular arrhythmia will be higher than the estimates presented.

\section{IS EXERCISE BENEFICIAL IN PATIENTS WITH HCM?}

Recent studies have demonstrated that exercise is beneficial for older patients with HCM. The Randomized Exploratory Study of Exercise Training in Hypertrophic Cardiomyopathy trial established that 16 weeks of moderate-intensity exercise resulted in a small but significant increase in exercise capacity in older adult patients (mean age 50.4 years) with HCM. $^{42}$ These modest increases in cardiorespiratory fitness may be associated with reductions in cardiovascular mortality. ${ }^{43}$ Likewise, a retrospective survey of adult patients with HCM (mean age 49 years) suggested that lifetime vigorous exercise correlated with favourable diastolic function and was not associated with ventricular arrhythmias. ${ }^{44} \mathrm{~A}$ supervised cardiac rehabilitation exercise programme in symptomatic patients with HCM (mean age $62 \pm 13$ years) also demonstrated improved functional capacity. ${ }^{45}$ While these studies inform activity recommendations for older adult patients with HCM, they were not designed to establish safety in adolescent and young adult competitive athletes where the disease course and exercise intensity may be profoundly different.

\section{EVENTS DURING REST, SLEEP OR EXERCISE?}

While the occurrence of SCA/SCD during exercise is well documented in patients with HCM, there is debate if exercise itself presents a higher risk than more sedentary activity. This controversy was recently fueled by a 2019 study examining HCMrelated SCD in the general (non-athlete) population (median age 35 years) in Ontario, Canada, that reported $71 \%$ of cases occurred during sleep, rest or light activity. ${ }^{46}$ Similarly, in a study of 196 decedents with HCM (age $43 \pm 18$ years) reviewed by a specialist cardiac pathology centre in the UK, SCD during exercise occurred in just $46(23 \%)$ individuals but was confined to 
Table 1 Estimated annual mortality rate from sudden cardiac death in young athletes with HCM

Modellingassumptions:

- Prevalence of HCM in the athlete population ranges from 1:2000 to 1:500 persons.

- Supposing 500000 athletes, the total number of athletes with HCM is $250-1000$ persons.

- Annual incidence rates cited include only SCD and do not include resuscitated cardiac arrest; thus actual rates of all life-threatening ventricular arrhythmias will be higher.

- Proportion of SCD from HCM listed is based on autopsy confirmation or in vivo diagnosis.

\begin{tabular}{|c|c|c|c|c|c|}
\hline $\begin{array}{l}\text { Study and athlete } \\
\text { population }\end{array}$ & $\begin{array}{l}\text { Annual incidence of SCD (athlete- } \\
\text { years) }\end{array}$ & $\begin{array}{l}\text { Total Number of SCD } \\
\text { Cases (in a population of } \\
500000 \text { ) }\end{array}$ & $\begin{array}{l}\text { Proportion of SCD } \\
\text { from HCM }\end{array}$ & $\begin{array}{l}\text { Number of Cases of } \\
\text { SCD from HCM }\end{array}$ & $\begin{array}{l}\text { Annual mortality rate } \\
\text { from HCM-related SCD }\end{array}$ \\
\hline \multicolumn{6}{|l|}{ Maron et $a l^{19}$} \\
\hline College athletes & 1:62500 & 8 & $32.80 \%$ & 2.6 & $0.26 \%-1.0 \%$ \\
\hline Black college athletes & $1: 26315$ & 19 & $44.70 \%$ & 8.5 & $0.85 \%-3.4 \%$ \\
\hline White college athletes & 1:142857 & 3.5 & $44.70 \%$ & 1.6 & $0.2 \%-0.6 \%$ \\
\hline \multicolumn{6}{|l|}{ Harmon et al ${ }^{1}$} \\
\hline College athletes & $1: 53703$ & 9.3 & $8 \%$ & 0.7 & $0.07 \%-0.3 \%$ \\
\hline Black college athletes & $1: 21491$ & 23.3 & $8 \%$ & 1.9 & $0.2 \%-0.8 \%$ \\
\hline White college athletes & $1: 68354$ & 7.3 & $8 \%$ & 0.6 & $0.06 \%-0.2 \%$ \\
\hline $\begin{array}{l}\text { Division I male } \\
\text { basketball }\end{array}$ & $1: 5200$ & 96.2 & $8 \%$ & 7.7 & $0.8 \%-3 \%$ \\
\hline \multicolumn{6}{|c|}{ Maron et $a l^{\beta}$ From the US national registry } \\
\hline Black/minority athletes & $1: 12778$ & 39.1 & $42 \%$ & 16.4 & $1.6 \%-6.6 \%$ \\
\hline White athletes & $1: 60746$ & 8.2 & $31 \%$ & 2.6 & $0.3 \%-1.0 \%$ \\
\hline \multicolumn{6}{|l|}{ Harmon et $a^{22}$} \\
\hline $\begin{array}{l}\text { Male high school } \\
\text { athletes }\end{array}$ & $1: 68742$ & 7.3 & $14 \%$ & 1 & $0.1 \%-0.4 \%$ \\
\hline $\begin{array}{l}\text { Female high school } \\
\text { athletes }\end{array}$ & $1: 316679$ & 1.6 & $14 \%$ & 0.2 & $0.02 \%-0.08 \%$ \\
\hline \multicolumn{6}{|l|}{ Malhotra et $a l^{20}$} \\
\hline $\begin{array}{l}\text { Elite adolescent soccer } \\
(95 \% \text { male })^{*}\end{array}$ & 1:14794 & 33.8 & $37.50 \%$ & 12.7 & $1.3 \%-5.1 \%$ \\
\hline \multicolumn{6}{|l|}{ Corrado et $a P^{22}$} \\
\hline $\begin{array}{l}\text { Competitive } \\
\text { athletes } \leq 35 \text { years old } \\
\text { from Veneto region of } \\
\text { Italy } t\end{array}$ & $1: 62500$ & 8 & $2 \%$ & 0.2 & $0.02 \%-0.08 \%$ \\
\hline
\end{tabular}

*Study population underwent cardiovascular screening with ECG and echocardiogram at age 16 years.

tStudy population underwent annual cardiovascular screening with ECG.

HCM, hypertrophic cardiomyopathy; SCD, sudden cardiac death.

younger male subjects (age $30 \pm 11$ years). ${ }^{47}$ Comorbid obstructive sleep apnea which may be more common in older patients with HCM has been proposed as a risk factor for SCD during sleep, although evidence is limited. ${ }^{48}$ In younger athletes who engage in intensive training more regularly, SCD during exercise appears to be more common. In a study of 1306 cases of SCD in young athletes including 302 from HCM, $74 \%$ of events occurred during practice or competition. ${ }^{3}$ In a cohort of 79 cases of SCD in college athletes ( $8 \%$ from HCM), $56 \%$ occurred with exertion, $22 \%$ at rest and $14 \%$ during sleep (9\% unknown). ${ }^{1}$ In a prospective series of 179 cases of SCA/SCD in US competitive athletes, $76.0 \%$ occurred during or within 1 hour of exercise and $21.8 \%$ during rest or sleep ( $2.2 \%$ unknown). ${ }^{2}$ Additional reports from Sweden and Spain also found cardiomyopathy to be the most common cause of exercise-related SCD in athletes. ${ }^{49} 50$

Histopathologically, HCM presents an unpredictable arrhythmogenic substrate demonstrating myocardial disarray and interstitial and myocardial scarring as a result of microvascular ischaemia. ${ }^{29}$ Athletes engaging in intense exercise undergo powerful epinephrine surges, extreme metabolic stresses and dehydration, all of which could provoke a ventricular tachyarrhythmia in the setting of a pathological myocardial substrate. The effect of physiological cardiac adaptations potentially augmenting pathological hypertrophy in athletes with HCM raises additional concern. In a 2019 study of American football players, weight gain and increased systolic blood pressure were associated with development of a pathological cardiovascular phenotype consisting of concentric LVH, arterial stiffening and reduced left ventricular diastolic function. ${ }^{51}$ The potential adverse consequences of maladaptive cardiac remodelling in athletes with a genetic cardiomyopathy are unknown but potentially troubling. Could exercise-induced substrate changes in patients with HCM make sudden death at any time (during rest or physical exertion) more likely?

The proportion of athletes with SCA/SCD during exercise is further magnified considering vigorous exercise only accounts for one-sixth or less of the total hours in the day even in the most dedicated athletes. Thus, while SCA/SCD can occur at any time in patients with HCM, evidence suggests that intense exercise is a risk factor for potentially lethal ventricular tachyarrhythmias, especially in younger male individuals.

\section{DOES DISQUALIFICATION IN ATHLETES WITH HCM DECREASE SCD?}

While limited evidence is available, two prospective studies in young competitive athletes provide important insights into whether stopping competitive sports reduces mortality in athletes diagnosed with 
HCM. A 1998 study reported on 33335 screened athletes (mean age 19 years) from the Veneto region of Italy. ${ }^{52} \mathrm{HCM}$ was identified in 22 athletes, all of whom were disqualified from competitive sport and survived over 8 years of follow-up. One athlete with undetected HCM died, compared with 16 HCM-related deaths in the unscreened (non-athlete) general population. While the study was not powered to provide definitive conclusions, early detection of HCM in competitive athletes followed by sports disqualification led to a $73 \%$ risk reduction in mortality. ${ }^{52}$ Similarly, 11168 elite adolescent soccer players (mean age 16.4 years) from the UK underwent cardiovascular screening and were followed for a mean of 10.6 years. ${ }^{20}$ Five athletes were diagnosed with HCM through screening; three athletes stopped competitive soccer and survived, while two athletes continued playing against medical advice and died during exercise. $^{20}$

\section{POTENTIAL HARMS OF DISQUALIFICATION}

The disqualification of a young athlete from competitive sports is a complex and difficult decision that requires serious considerations. Not surprisingly, athletes diagnosed with potentially lethal cardiac disorders are at risk for significant psychological distress. ${ }^{53}$ Sports participation establishes healthy lifestyles, builds self-confidence and provides an avenue to educational scholarships or the potential financial rewards of professional sport that may carry different significance depending on the athlete's socioeconomic background. Athletic dedication and success also are integral to the self-identify of a young athlete, and removal from competitive sports likely will have short-term and possibly long-term consequences on mental and emotional health. In addition, risk tolerance or avoidance is an individual assessment and important for patient autonomy in healthcare decisions.

A 2014 study examined the psychological impact of being diagnosed with a serious or potentially lethal cardiac disease in 25 young competitive athletes, including 3 athletes with HCM that were ultimately disqualified. ${ }^{54}$ Athletes progressed through four psychological stages following sports disqualification including: (1) immediate challenges to athlete identity, (2) grief/coping, (3) adaptation and (4) acceptance. ${ }^{54}$ Risk factors for increased psychological morbidity included a higher level of competition, permanent disqualification from sports, persistent reminders of their disease (eg, daily medication, monitoring heart rate during activity) and unanticipated outcomes (eg, failed procedures). Additionally, disqualified athletes were at risk for losing the structure and support afforded by a team environment, and elite or professional athletes may have difficulty shifting to an alternative career. However, early diagnosis also led to new goals such as mentoring or coaching. Remarkably, all athletes diagnosed through advanced cardiovascular screening stated they would repeat the process, suggesting SCD risk reduction was accepted over sports particpation. ${ }^{54}$

Thus, the potential harms of sports disqualification-loss of self-identity, loss of educational scholarship, loss of potential income and the risk of depression or mental health issues-should be carefully weighed and addressed in the shared decision-making process. Regardless of the outcome, mechanisms to provide emotional and psychological support for athletes diagnosed with a potentially career altering heart condition should be in place. In addition, while difficult to replace the social and psychological benefits of competitive sports, a programme that maintains safe levels of physical activity and cardiorespiratory fitness should be advised for athletes no longer participating in competitive sports. Studies defining the specifics of such programmes are still in the developmental stages.

\section{LIMITATIONS OF SHARED DECISION-MAKING}

Other issues warrant consideration in the context of life-critical shared decision-making. Most young athletes do not consider themselves vulnerable to the risks of sport, catastrophic injury or sudden death. In combination with the lure of fame and/or fortune or family pressure for economic gain, this raises an important ethical question: can young athletes truly make an unbiased and informed decision under duress?

Educational institutions, clubs and sports organisations also are impacted by the decision. High school and college administrations have a responsibility to protect the health and safety of their student athletes and potential liability concerns may shape a more conservative risk tolerance. In professional sports, some clubs may be adverse to even the small prospect of a player suffering SCA/SCD during a widely publicised event.

Medical team members, including team physicians and cardiologists, also may view eligibility decisions from different perspectives. Team physicians commonly provide medical 'clearance' to play sports. A determination of safety and eligibility is required for every athlete at the time of their preparticipation evaluation. Outside of cardiovascular concerns, team physicians periodically place activity restrictions or even permanent eligibility restrictions in other areas relevant to the health and safety of athletes-such as repetitive concussions, cervical spinal stenosis, or worsening joint degeneration-in which the competitive career of an athlete is stopped prematurely. While the best interest of the athlete is always the top priority, sports medicine professionals also may have an obligation to their club and an ethical responsibility to society to ensure safe athletic participation.

Consequently, in the setting of different perspectives or perhaps even 'competing interests', how does the shared decision-making process move forward?

\section{WHO ULTIMATELY DECIDES?}

Ideally, an informed athlete will come to the same conclusion about sports participation as their medical team. However, the athlete, team physician, cardiologist, athletic trainer and school or club may have different thresholds to permit a return to competitive sports. For instance, what happens when the cardiologist recognises an athlete with HCM has an elevated risk of SCD but supports the athlete's right to choose to play and the team physician recommends against it? Or if the team cardiologist/ consultant recommends against participation but the athlete's cardiologist or second opinion endorses a return to play? If all parties do not agree, shared decision-making ultimately comes down to who has the final authority to give the 'yes' or 'no' regarding eligibility. Allowing the athlete to make the final decision may unintentionally remove everyone else from the shared-decision-making process. Undoubtedly, balancing patient autonomy with respect for the common good in order to prevent catastrophic events in sport is a massive challenge. A proposed framework to consider competitive sports restriction in athletes based on the risk of HCM-related SCD is provided in figure 1.

In the USA, legal precedent supports that high school students with heart disease have no compelling right to participate in interscholastic sports without medical clearance and that college athletes with life-threatening cardiac conditions can be medically disqualified and eligibility decisions reside with the team physician. ${ }^{556}$ Some professional sports leagues, such as the National Football League (NFL), also explicitly state in the collective bargaining agreement with the NFL Players Association that the head team physician for each club has final decision authority. In 


\section{Competitive Sports Restriction}

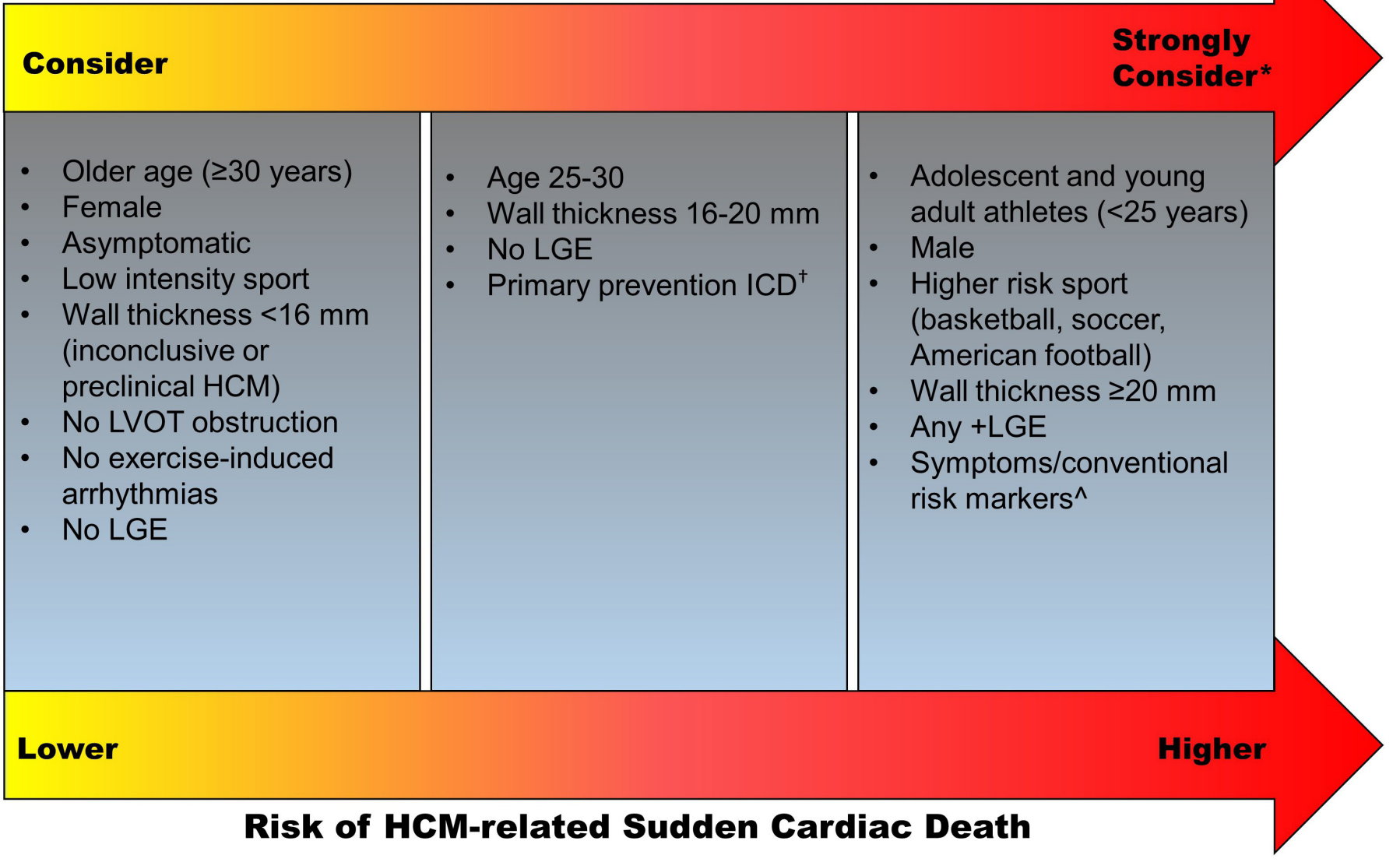

Figure 1 Proposed framework for eligibility decisions in athletes with HCM. HCM, hypertrophic cardiomyopathy; ICD, implantable cardioverter defibrillator; LGE, late gadolinium enhancement; LVOT left ventricular outflow tract. * Strongly consider competitive sport restriction in individuals with multiple risk factors. ${ }^{\dagger} \mathrm{ICD}$ s lower the risk of HCM-related SCD, but recommendations for an ICD are based on conventional high-risk markers and an ICD should not be placed for the sole purpose of allowing sports participation. 'Conventional risk markers include: family history of HCM-related sudden death, unexplained syncope, multiple or repetitive episodes of non-sustained ventricular tachycardia, massive left ventricular hypertrophy (wall thickness $\geq 30 \mathrm{~mm}$ ), left ventricular apical aneurysm or an ejection fraction $<50 \%$.

some instances, one team may judge an athlete at unacceptable risk, while another, presented with the same evidence, may allow the athlete to participate. In Italy, guidelines for sports eligibility in athletes with heart disease is actually written into law. ${ }^{57}$ Thus, eligibility decisions may be influenced by the policies and laws dictated by the relevant country or sports governing body.

\section{CONCLUSION}

The diagnosis of serious cardiovascular disease in a competitive athlete presents complex issues regarding safety, patient autonomy and medical decision-making engrossed by scientific and clinical uncertainty. For disorders where effective risk reduction is supported by evidence, continued sports participation in treatment-compliant patients seems reasonable. HCM comprises an electrophysiological substrate that is unpredictable and potentially vulnerable to the stresses of intense exercise even in the absence of conventional risk markers. Epidemiological evidence indicates that HCM is an important cause of SCD in young athletes and sports restriction may prevent SCD. However, the quality of evidence is not sufficient to precisely define risk across all athletes diagnosed with HCM, making eligibility decisions very challenging in the era of shared decisionmaking. In addition, we lack adequately powered studies that investigate safety with exercise and HCM, particularly in young athletes participating in competitive sport who appear to be at greater risk. While moderate-intensity exercise seems beneficial in older patients
What is already known

Sudden cardiac death $(\mathrm{SCD})$ is the leading cause of nontraumatic fatalities in young competitive athletes $(<30$ years old) during sports and exercise.

- Evidence supports that hypertrophic cardiomyopathy (HCM) is consistently represented in SCD series in young athletes, deeming it an important cause of SCD in young athletes.

- Guidelines for sports participation in athletes with SCDassociated cardiovascular conditions have evolved where the treatment options, potential harms and benefits of continued sports participation and patient values are discussed within a shared decision-making model.

with HCM, high-intensity training in young athletes with HCM may trigger life-threatening ventricular tachyarrhythmias. We estimate an annual risk of $0.1 \%-6.6 \%$ for the occurrence of SCD in adolescent or young adult competitive athletes with HCM. Higher risk is exhibited in males and athletes participating in basketball, soccer and American football. Risk stratification tools have been developed for the clinical management of patients with HCM. These were not derived from athletic populations and do not consider some of the unique considerations raised in this review. However, until a suitable alternative 
What are the new findings

- A critical review of the evidence confirms that young age is the period of highest risk for unexpected SCD in patients with HCM.

- No study to date directly supports the safety of young athletes with HCM participating in competitive sports, while limited data suggest that disqualification from competitive sports may prevent SCD.

- Although precisely quantifying the risk of SCD with HCM is challenging, we estimate, based on available evidence, that the risk of $\mathrm{HCM}$-related SCD in young athletes ranges from $0.1 \%$ to $6.6 \%$ per year, with higher mortality rates in male athletes and athletes in higher risk sports such as basketball, soccer and American football.

- Shared decision-making in sports cardiology involves a complex discussion of risk that must balance scientific evidence, clinical uncertainty, patient autonomy and concerns from all parties impacted by a decision to participate in competitive sport.

is available, these prognostic tools can be used with caution. Shared decision-making implies that the anticipated risk is acceptable to the patient, family, medical team and club/school. Based on this critical analysis, competitive sports participation in young athletes with HCM should be approached with caution, appropriate counselling and careful consideration for sports restriction based on HCMrelated SCD risk. Additional research is needed to determine safe levels of exercise and sports participation in young persons with HCM and to develop evidence-based SCD risk stratification algorithms in athletes.

Correction notice This article has been corrected since it published Online First. The provenance and peer review statement has been included.

Twitter Jonathan A Drezner @DreznerJon, Aneil Malhotra @DrAneilMalhotra, Jordan M Prutkin@jordanprutkin, Michael Papadakis@MichaelPapadak2, Kimberly G Harmon @DrKimHarmon, Irfan M Asif @IrfAsif and Sanjay Sharma @SSharmacardio

Contributors JAD was involved in the conception, design, drafting, critical revision, and approval of the manuscript. AM, KGH, IMA, DSO, and JCM were involved in the conception, design, critical revision, and approval of the manuscript. JMP, MP, and SS were involved in the critical revision and approval of the manuscript. All authors agree to be accountable for all aspects of the work and ensure the integrity of the manuscript.

Funding The authors have not declared a specific grant for this research from any funding agency in the public, commercial or not-for-profit sectors.

\section{Competing interests None declared.}

Patient consent for publication Not required.

Provenance and peer review Not commissioned; externally peer reviewed.

Open access This is an open access article distributed in accordance with the Creative Commons Attribution Non Commercial (CC BY-NC 4.0) license, which permits others to distribute, remix, adapt, build upon this work non-commercially, and license their derivative works on different terms, provided the original work is properly cited, appropriate credit is given, any changes made indicated, and the use is non-commercial. See: http://creativecommons.org/licenses/by-nc/4.0/.

\section{ORCID iDs}

Jonathan A Drezner http://orcid.org/0000-0003-3519-9120

Aneil Malhotra http://orcid.org/0000-0002-8670-3764

Kimberly G Harmon http://orcid.org/0000-0002-3670-6609

\section{REFERENCES}

1 Harmon KG, Asif IM, Maleszewski JJ, et al. Incidence, cause, and comparative frequency of sudden cardiac death in national collegiate athletic association athletes: a decade in review. Circulation 2015;132:10-19.
2 Peterson DF, Siebert DM, Kucera KL, et al. Etiology of sudden cardiac arrest and death in US competitive athletes: a 2-year prospective surveillance study. Clin I Sport Med 2020;30:305-14

3 Maron BJ, Haas TS, Ahluwalia A, et al. Demographics and epidemiology of sudden deaths in young competitive athletes: from the United States national registry. Am J Med 2016;129:1170-7.

4 Drezner JA, O'Connor FG, Harmon KG, et al. AMSSM position statement on cardiovascular Preparticipation screening in athletes: current evidence, knowledge gaps, recommendations and future directions. Br J Sports Med 2017;51:153-67.

5 Maron BJ, Zipes DP. 36Th Bethesda conference: eligibility recommendations for competitive athletes with cardiovascular abnormalities. J Am Coll Cardiol 2005;45:1312-77.

6 Pelliccia A, Fagard R, Bjørnstad HH, et al. Recommendations for competitive sports participation in athletes with cardiovascular disease: a consensus document from the study group of sports cardiology of the Working group of cardiac rehabilitation and exercise physiology and the Working group of myocardial and pericardial diseases of the European Society of cardiology. Eur Heart J 2005;26:1422-45.

7 Maron BJ, Udelson JE, Bonow RO, et al. Eligibility and Disqualification recommendations for competitive athletes with cardiovascular abnormalities: Task force 3: hypertrophic cardiomyopathy, arrhythmogenic right ventricular cardiomyopathy and other cardiomyopathies, and myocarditis: a scientific statement from the American heart association and American College of cardiology. Circulation 2015; 132:e273-80.

8 Pelliccia A, Solberg EE, Papadakis M, et al. Recommendations for participation in competitive and leisure time sport in athletes with cardiomyopathies, myocarditis, and pericarditis: position statement of the sport cardiology section of the European association of preventive cardiology (EAPC). Eur Heart J 2019;40:19-33.

9 Pelliccia A, Caselli S, Pelliccia M, et al. Clinical outcomes in adult athletes with hypertrophic cardiomyopathy: a 7-year follow-up study. Br J Sports Med 2020;54:1008-12.

10 Baggish AL, Ackerman MJ, Lampert R. Competitive sport participation among athletes with heart disease: a call for a paradigm shift in decision making. Circulation 2017; 136:1569-71.

11 Maron BJ, Nishimura RA, Maron MS. Shared decision-making in HCM. Nat Rev Cardiol 2017; 14:125-6.

12 Drezner JA. Detect, manage, inform: a paradigm shift in the care of athletes with cardiac disorders? Br J Sports Med 2013;47:4-5.

13 Johnson JN, Ackerman MJ. Return to play? Athletes with congenital long QT syndrome. Br J Sports Med 2013:47:28-33.

14 Aziz PF, Sweeten T, Vogel RL, et al. Sports participation in genotype positive children with long QT syndrome. JACC Clin Electrophysiol 2015;1:62-70.

15 Sawant AC, Bhonsale A, te Riele ASJM, et al. Exercise has a disproportionate role in the pathogenesis of arrhythmogenic right ventricular dysplasia/cardiomyopathy in patients without desmosomal mutations. J Am Heart Assoc 2014;3:e001471.

16 Ruwald A-C, Marcus F, Estes NAM, et al. Association of competitive and recreational sport participation with cardiac events in patients with arrhythmogenic right ventricular cardiomyopathy: results from the North American multidisciplinary study of arrhythmogenic right ventricular cardiomyopathy. Eur Heart J 2015;36:1735-43.

17 James CA, Bhonsale A, Tichnell C, et al. Exercise increases age-related penetrance and arrhythmic risk in arrhythmogenic right ventricular dysplasia/cardiomyopathyassociated desmosomal mutation carriers. J Am Coll Cardiol 2013;62:1290-7.

18 Corrado D, Link MS, Calkins H. Arrhythmogenic right ventricular cardiomyopathy. N Engl J Med 2017;376:61-72.

19 Maron BJ, Haas TS, Murphy CJ, et al. Incidence and causes of sudden death in U.S. college athletes. J Am Coll Cardiol 2014;63:1636-43.

20 Malhotra A, Dhutia H, Finocchiaro G, et al. Outcomes of cardiac screening in adolescent soccer players. N Engl J Med 2018;379:524-34.

21 Finocchiaro G, Papadakis M, Robertus J-L, et al. Etiology of sudden death in sports: insights from a United Kingdom regional registry. J Am Coll Cardiol 2016;67:2108-15.

22 Harmon KG, Asif IM, Maleszewski JJ, et al. Incidence and etiology of sudden cardiac arrest and death in high school athletes in the United States. Mayo Clin Proc 2016;91:1493-502.

23 Maron BJ, Roberts WC, Epstein SE. Sudden death in hypertrophic cardiomyopathy: a profile of 78 patients. Circulation 1982;65:1388-94.

24 Maron BJ, Olivotto I, Spirito P, et al. Epidemiology of hypertrophic cardiomyopathyrelated death: revisited in a large non-referral-based patient population. Circulation 2000;102:858-64.

25 Cardim N, Brito D, Rocha Lopes L, et al. The Portuguese registry of hypertrophic cardiomyopathy: overall results. Rev Port Cardiol 2018;37:1-10.

26 Maron BJ, Henry WL, Clark CE, et al. Asymetric septal hypertrophy in childhood. Circulation 1976;53:9-19.

27 McKenna WJ, Deanfield JE. Hypertrophic cardiomyopathy: an important cause of sudden death. Arch Dis Child 1984;59:971-5.

28 Moak JP, Leifer ES, Tripodi D, et al. Long-term follow-up of children and adolescents diagnosed with hypertrophic cardiomyopathy: risk factors for adverse arrhythmic events. Pediatr Cardiol 2011;32:1096-105. 
29 Maron BJ. Clinical course and management of hypertrophic cardiomyopathy. N Eng/ J Med 2018;379:655-68.

30 Maron BJ, Rowin EJ, Casey SA, et al. Hypertrophic cardiomyopathy in children, adolescents, and young adults associated with low cardiovascular mortality with contemporary management strategies. Circulation 2016;133:62-73.

31 Maron BJ, Maron MS. Contemporary strategies for risk stratification and prevention of sudden death with the implantable defibrillator in hypertrophic cardiomyopathy. Heart Rhythm 2016;13:1155-65.

32 Maron BJ, Rowin EJ, Casey SA, et al. How hypertrophic cardiomyopathy became a contemporary treatable genetic disease with low mortality: shaped by 50 years of clinical research and practice. JAMA Cardiol 2016;1:98-105.

33 Maron MS, Rowin EJ, Wessler BS, et al. Enhanced American College of Cardiology/American heart association strategy for prevention of sudden cardiac death in high-risk patients with hypertrophic cardiomyopathy. JAMA Cardiol 2019:4:644-57.

34 Lampert R, Olshansky B, Heidbuchel H, et al. Safety of sports for athletes with implantable cardioverter-defibrillators: results of a prospective, multinational registry. Circulation 2013;127:2021-30.

35 Maron BJ, Carney KP, Lever HM, et al. Relationship of race to sudden cardiac death in competitive athletes with hypertrophic cardiomyopathy. J Am Coll Cardiol 2003:41:974-80.

36 Sheikh N, Papadakis M, Panoulas VF, et al. Comparison of hypertrophic cardiomyopathy in Afro-Caribbean versus white patients in the UK. Heart 2016:102:1797-804

37 Di Paolo FM, Schmied C, Zerguini YA, et al. The athlete's heart in adolescent Africans: an electrocardiographic and echocardiographic study. J Am Coll Cardiol 2012;59:1029-36.

38 Sheikh N, Papadakis M, Carre F, et al. Cardiac adaptation to exercise in adolescent athletes of African ethnicity: an emergent elite athletic population. Br J Sports Med 2013;47:585-92.

39 Basavarajaiah S, Wilson M, Whyte G, et al. Prevalence of hypertrophic cardiomyopathy in highly trained athletes: relevance to pre-participation screening. J Am Coll Cardiol 2008:51:1033-9.

40 Sheikh N, Papadakis M, Schnell F, et al. Clinical profile of athletes with hypertrophic cardiomyopathy. Circ Cardiovasc Imaging 2015;8:e003454.

41 Drezner JA, Peterson DF, Siebert DM, et al. Survival after Exercise-Related sudden cardiac arrest in young athletes: can we do better? Sports Health 2019;11:91-8.

42 Saberi S, Wheeler M, Bragg-Gresham J, et al. Effect of moderate-intensity exercise training on peak oxygen consumption in patients with hypertrophic cardiomyopathy: a randomized clinical trial. JAMA 2017;317:1349-57.
43 Dias KA, Link MS, Levine BD. Exercise Training for Patients With Hypertrophic Cardiomyopathy: JACC Review Topic of the Week. J Am Coll Cardiol 2018;72:1157-65

44 Dejgaard LA, Haland TF, Lie $\mathrm{OH}$, et al. Vigorous exercise in patients with hypertrophic cardiomyopathy. Int J Cardiol 2018;250:157-63.

45 Klempfner R, Kamerman T, Schwammenthal E, et al. Efficacy of exercise training in symptomatic patients with hypertrophic cardiomyopathy: results of a structured exercise training program in a cardiac rehabilitation center. Eur J Prev Cardiol 2015;22:13-19.

46 Weissler-Snir A, Allan K, Cunningham K, et al. Hypertrophic cardiomyopathyrelated sudden cardiac death in young people in Ontario. Circulation 2019;140:1706-16.

47 Finocchiaro G, Papadakis M, Tanzarella G, et al. Sudden death can be the first manifestation of hypertrophic cardiomyopathy: data from a United Kingdom pathology registry. JACC Clin Electrophysiol 2019;5:252-4.

48 Aggarwal S, Jan MF, Agarwal A, et al. Hypertrophic cardiomyopathy associated with sleep apnea: serious implications and COGENT management strategy. Expert Rev Cardiovasc Ther 2015;13:277-84.

49 Morentin B, Suárez-Mier MP, Monzó A, et al. Sports-Related sudden cardiac death due to myocardial diseases on a population from 1-35 years: a multicentre forensic study in Spain. Forensic Sci Res 2019;4:257-66.

50 Wisten A, Börjesson M, Krantz P, et al. Exercise related sudden cardiac death (SCD) in the young - Pre-mortal characterization of a Swedish nationwide cohort, showing a decline in SCD among athletes. Resuscitation 2019;144:99-105.

$51 \mathrm{Kim} \mathrm{JH}$, Hollowed C, Liu C, et al. Weight gain, hypertension, and the emergence of a maladaptive cardiovascular phenotype among US football players. JAMA Cardiol 2019;4:1221.

52 Corrado D, Basso C, Schiavon M, et al. Screening for hypertrophic cardiomyopathy in young athletes. N Engl J Med 1998;339:364-9.

53 Asif IM, Price DE, Ewing A, et al. The impact of diagnosis: measuring the psychological response to being diagnosed with serious or potentially lethal cardiac disease in young competitive athletes. Br J Sports Med 2016;50:163-6.

54 Asif IM, Price D, Fisher LA, et al. Stages of psychological impact after diagnosis with serious or potentially lethal cardiac disease in young competitive athletes: a new model. J Electrocardio/ 2015:48:298-310.

55 Paterick TE, Paterick TJ, Fletcher GF, et al. Medical and legal issues in the cardiovascular evaluation of competitive athletes. JAMA 2005:294:3011-8.

56 Maron BJ, Mitten MJ, Quandt EF, et al. Competitive athletes with cardiovascular disease--the case of Nicholas Knapp. N Engl J Med 1998:339:1632-5.

57 Biffi A, Delise P, Zeppilli P, et al. Italian cardiological guidelines for sports eligibility in athletes with heart disease: Part 1. J Cardiovasc Med 2013:14:477-99. 